\title{
Immigration: new challenges for psychiatry and mental health services in Ireland
}

\author{
Anthony W Clare
}

Ir J Psych Med 2002; 19(1): 3

The growing arrival of immigrants in Ireland, particularly from Eastern Europe, Africa and Asia, poses major challenges to Irish society. Psychiatry and the mental health services are not spared. For many immigrants, particularly those who come to Ireland, their journey has been precipitated by political or religious discrimination, by famine, or by war. For these reasons they are at particular risk of developing physical and/or mental ill-health, and there is a substantial, rich and growing literature testifying to this fact.

This is highlighted in this issue with two papers by Kennedy et al (page 4) and Feeney et al (page 29). These papers are a timely reminder of the psychological implications of immigration to Ireland, not merely on the migrants themselves but on society at large.

Immigration does represent a remarkable opportunity for Irish mental health researchers to participate in the study and elucidation of the variability of different symptoms, syndromes and disorders between different cultures. The arrival in our midst of large numbers of people who do not share our language, religious beliefs or cultural attitudes facilitates not merely the study of the impact of change on migrants but also enables us to take a closer and more informed look at those aspects of Irish culture which reflect and strengthen mental health, and those aspects which threaten it.

Much psychiatric research is focused on immigrants and on such issues as higher rates of psychosis, ${ }^{1,2}$ differences in treatment outcomes, ${ }^{3,4}$ differences in prevalence of different psychiatric disorders between immigrants, second generation immigrants and indigenous populations, ${ }^{5-8}$ and mental health differences between different migrant communities. ${ }^{9-12}$

Given such an emphasis on psychopathology, it is important that we remind ourselves that immigration in itself is not always associated with a proneness to disease. Indeed, it has been long shown that immigrants coming to live among fellow immigrants and able to continue to participate in and contribute to their own culture, as well as that of their new abode. They also enjoy a greater degree of social buffering and protection against the adverse consequences of social discontinuity than do those who are suddenly exposed to an alien community and cut off from their cultural contemporaries.

It is not simply moving from one country to another that causes a deterioration in health. What is particularly challenging for the immigrant is the abrupt exposure to social demands and expectations that are different, strange, and intimidating. The process of adapting to the challenges of adaptation and familiarisation has been

Anthony W Clare, MD, FRCP, FRCPI, FRCPsych, MPhil, Professor of Psychiatry, St Edmundsbury, Lucan, Co Dublin, Ireland described as 'cultural mobility'13 and may well be an important factor in any increased predisposition to ill health. The converse - robust health in the face of the challenges of migration - has been attributed to sturdy rapport and frequent social interchange between the individual migrant and their new social environment. ${ }^{14}$

And therein lies the challenge for Irish society as it confronts the novelty of immigration. How does it ensure that the immigrant can simultaneously draw on the social supports and bonds of his or her own culture and benefit from the best and richest aspects of Irish life?

As mental health professionals we are understandably concerned with diagnostic and treatment implications of illnesses occurring in people from cultures and traditions with which professionals staffing the Irish mental health services are, for the most part, unfamiliar. There are, however, much wider issues, not least how Ireland can respond to large-scale immigration without an increase in racial discrimination, prejudice and stigmatisation.

This is a pressing issue, given that in the Principles for the Protection of Persons with Mental Illness and the Improvement of Mental Health Care adopted by the UN General Assembly in December 1991, specific mention is made of the right of every patient to receive psychiatric treatment suited to his or her cultural background. The implications for the training of mental health professionals and the provision of appropriate treatment services are immense and pressing.

\section{References}

1. Selten JP, Sijben N. First admission rates for schizophrenia in immigrants to the Netherlands. The Dutch National Register Social Psychiatry and Psychiatric Epidemiology 1994; 29: 71-7.

2. Sharpley MS, Hutchinson C, McKenzie K, Murray RM. Understanding the excess of psychosis among the African-Caribbean population in England: review of current hypotheses. $\mathrm{Br}$ J Psychiatry 2001; Suppl. 40, 60-8.

3, Bhugra D, Leff J, Mallett R et al. Incidence and outcome of schizophrenia in Whites, African Caribbeans and Asians in London. Psychological Medicine 1997; 27: 791-8.

4. McKenzie K, Samele, C, Van Horn E, Tattan T, Van Os J, Munay R. Comparison of the outcome and treatment of psychosis in people of Caribbean origin living in the UK and British Whites. Br J Psychiat 2001; 178, 160-5. 5. Bryant-Waugh R, Lask B. Anorexia nervosa in a group of Asian children living in Britain. Br J Psychiat 1991; 158, 229-33.

6. Hendrie HC, Osuntokun BO, Hall KS et al. Prevalence of Alzheimer's disease and dementia in two communities: Nigerian African and African Americans. Am J Psychiat 1995; 152: 1485-91.

7. Perkins P, Annegers JF, Doody RS et al. Incidence and prevalence of dementia in a multiethnic cohort on municipal retirees. Neurology 1997; 49:44-50.

8. Livingston O, Leavey G, Kitchen M, Manela S, Sembhi S, Katona C. Mental health of migrant elders - the Islington study. Br J Psychiat 2001; 179: 361 6. 9. Blakemore K. Health and illness among the elderly of minority elderly groups living in Birmingham: some new findings Health Trend; 1982; 14, 69-72

10. Blazer DG, Landerman LR, Hays JC et al. Symptoms of depression among community dwelling elderly Afican-African and white older adults. Psychological Medicine 1998; 28; 1311-20.

11. Leavey G. Suicide and Irish migrants in Britain: identity and integration. International Review of Psychiatry 1999; 11: 168-172.

12. Cochrane R, Bal SS. Mental hospital admission rates of immigrants to England: a comparison of 1971 and 1981. Social Psychiatry and Psychiatric Epidemiology 1989; 26: 2-11.

13. Syme SL, Hyman MM, Enterlin PE. Cultural mobility and the occurrence of coronary heart disease. Journal of Chronic Disease 1965; 26: 13-30.

14. Totman R. Social causes of illness, Souvenir Press, London, 1979. 